\title{
Self-harm as a predisposition for suicide attempts: A study of adolescents' deliberate self-harm, suicidal ideation, and suicide attempts
}

\author{
Tiago A. Duarte ${ }^{\mathrm{a}, \mathrm{b}, *}$, Sofia Paulino ${ }^{\mathrm{a}, \mathrm{b}}$, Carolina Almeida ${ }^{\mathrm{a}, \mathrm{c}}$, Hugo S. Gomes ${ }^{\mathrm{d}}$, Nazaré Santos ${ }^{\mathrm{a}, \mathrm{b}}$, \\ Maria Gouveia-Pereira ${ }^{\mathrm{e}}$ \\ ${ }^{a}$ Núcleo de Estudos de Suicídio (N.E.S.), Serviço de Psiquiatria e Saúde Mental do Hospital de Santa Maria, Centro Hospitalar Universitário Lisboa Norte, E.P.E., Av. Prof. \\ Egas Moniz, Lisbon 1649-035, Portugal \\ ${ }^{\mathrm{b}}$ Faculdade de Medicina, Universidade de Lisboa, Lisbon, Portugal \\ ${ }^{\mathrm{c}}$ Centro Hospitalar Lisboa Ocidental, E.P.E., Lisbon, Portugal \\ ${ }^{\mathrm{d}}$ Research Centre on Psychology (CIPsi), School of Psychology, University of Minho, Braga, Portugal \\ e ISPA- Instituto Universitário, CIE-ISPA, Lisbon, Portugal
}

\section{A R T I C L E I N F O}

\section{Keywords:}

Deliberate self-harm

Suicidal ideation

Suicide attempts

Adolescents

Suicide prevention

\begin{abstract}
A B S T R A C T
The aim of this study was to analyze the predictive risk factors for self-harm in adolescents with and without suicidal ideation. 600 adolescents answered a questionnaire about self-harm and suicidal behaviors. A logistic regression analysis was conducted. Over half of the individuals with deliberate self-harm (DSH) presented significant suicide risk. There was a direct association between DSH and suicide attempts, with almost the totality of the adolescents with suicide attempts also reporting DSH. According to the prediction model, suicidal ideation and diversity of DSH behaviors are significant predictors of suicide attempts, with an augmentation in the diversity of DSH behaviors and suicidal ideation predicting suicide attempts. Depression and anxiety appeared also as significant predictors of suicide attempts in adolescent self-harmers. Considering that the majority of the sample was not from a clinical setting, an alarming finding was that one third of the total sample was at suicide risk. These results place DSH as a key variable for early intervention.
\end{abstract}

\section{Introduction}

Self-harm, suicide attempts, and suicide are a public health problem not only in Portugal but also in several European countries (Naghavi, 2019). Self-harm is the act of deliberately causing harm to one-self; while suicide refers to the act of voluntarily causing your own death (Nock et al., 2008). Every year, about 800,000 human beings die from suicide. The global annual mortality rate in 2016 was 11.2 per 100,000 individuals, with variations across age groups and countries (Naghavi, 2019).

Suicide is the second-leading cause of death among adolescents between 10 and 19 years old (Bilsen, 2018). Evidence shows that selfharm behaviors vary throughout the life-cycle: the proportion of selfharm behaviors to suicide attempts ranges from 30:1 in young people to 3:1 in the elderly (Muehlenkamp et al., 2012).

World Health Organization data reveals that suicide rates in youth aged between 15 and 29 years have been stable, with 4 in every 100,000 in 2003 to 3.9 in every 100,000 in 2016, meaning that suicide is still a major public health issue (Carvalho et al., 2013; World Health
Organization, 2018). In 2011, the CASE Study revealed that, out of 30,477 adolescents (aged between 14 and 17 years) across six European countries, $2.6 \%$ reported single self-harm episodes in the past year, and $3.2 \%$ reported multiple episodes during the same period (Madge et al., 2011). Approximately $80 \%$ of the young people said they had not experienced thoughts of self-harm in the past year (Madge et al., 2011). Although rare, suicide in adolescents is a tragic outcome which must be actively prevented (Wasserman et al., 2005).

Adolescence and young adulthood are a period at risk for both suicide attempts and DSH (Muehlenkamp and Gutierrez, 2007) and thus, the ability to predict the self-harming adolescents at risk for suicidal behaviors is increasingly important (Brausch and Gutierrez, 2010; Paashaus et al., 2019).

Suicide and self-harm are heterogenous concepts with numerous terminologies describing them (Hamza et al., 2015; Meszaros et al., 2017; Preyde et al., 2012). Non-suicidal self-injury (NSSI) is the term proposed in the DSM-5 and reflects an intentional behavior, not socially accepted (so as to distinguish it from tattoos and piercings), which leads to the destruction or injury of body tissue without major physical injury

\footnotetext{
* Corresponding author.

E-mail addresses: tiago.antunes@chln.min-saude.pt (T.A. Duarte), mpereira@ispa.pt (M. Gouveia-Pereira).
} 
(American Psychiatric Association, 2013). This definition stresses the strategic nature of the action in order to reduce psychological distress and emphasizes the deliberate and non-suicidal purpose which implies intentionality (DSM-5). Of the other commonly used expressions, selfinjury and DSH stand out. Self-injury includes NSSI, as well as exposing oneself to violent situations, trichotillomania, and ingesting drugs. On the other hand, the term deliberate self-harm (DSH) comprises the NSSI behaviors and intentional drug overdoses. This terminology was developed to designate intentional, self-directed, and non-socially acceptable behaviors that are intended to cause destruction or impairment of the body, performed with or without conscious suicidal intention. Moreover, DSH is the term used in the Portuguese Plan for Suicide Prevention (Carvalho et al., 2013). Therefore, in the present article, we will use the term deliberate self-harm (DSH) to refer to NSSI behaviors and intentional drug overdoses.

Authors have argued that DSH behaviors should be seen as a protective factor against suicidal behavior (Brausch and Gutierrez, 2010; Castellví et al., 2017; Nock, 2009). According to these authors, by allowing the channelling of destructive impulses into a circumscribed area, people create an illusion of control over death. In fact, there is evidence suggesting that adolescents report DSH in order to lessen suicidal ideation (Linehan, 1993; Nock, 2009). On the other hand, other researchers suggest DSH as a risk factor for suicidal ideation or behavior (Cruz et al., 2013; Grandclerc et al., 2016). Empirical evidence shows that DSH and suicidal ideation share similar risk factors, namely psychiatric comorbidities (e.g. depression, borderline personality disorder, substance abuse, post-traumatic stress disorder, impulsivity, attention deficit, conduct disorder) and environmental factors (e.g. history of sexual abuse and physical violence, and familiar dysfunction) (Costa et al., 2019; Ghinea et al., 2019; Gouveia-Pereira et al., 2014; Kelada et al., 2016; Lipschitz et al., 2012).

DSH frequency is the strongest predictor of suicide after suicidal ideation (Barreto Carvalho et al., 2017). Guerreiro (Guerreiro et al., 2017) compared several groups of adolescents with regard to anxiety and depression, among which two subgroups were distinguished by the presence of DSH: non-repeated self-harmers (i.e. presented only one previous episode of DSH) and repeated self-harmers (i.e. presented multiple DSH episodes). Results showed that the subgroup of repeated self-harmers presented higher values of anxiety and depression. In addition, anxiety and depression were positively related to DSH, especially with the repetition of these behaviors. Numerous studies have consistently shown that adolescents with DSH have higher levels of depression, anxiety, and stress (Di Pierro et al., 2012; Gonçalves et al., 2012; Gutridge, 2010; Kiekens et al., 2015; Klemera et al., 2017).

There are several etiological models that seek to understand the suicidal spectrum behaviors. In Linehan's model (Linehan, 1993), for example, suicidal behaviors are considered direct or indirect consequences of a state of emotional deregulation or attempts to modulate intense emotional reactions. The construct of emotional dysregulation is based on the hypothesis that certain individuals present greater emotional sensitivity (i.e. low threshold of recognition or response to emotional stimuli), greater emotional reactivity (i.e. increased activity of the amygdala), and slower regression to the emotional basal state. Several studies indicate that emotions such as anger, anxiety, or frustration precede DSH behaviors, and cause a feeling of relief or calm in the short term, followed in the long term by sadness, guilt, anxiety, disgust, or anger (Lee, 2016; McMahon et al., 2010; Victor and Klonsky, 2014a; Wichstrøm, 2009; Zubrick et al., 2017).

The Gateway Theory (Brausch and Gutierrez, 2010; Hamza et al., 2012), on the other hand, proposes the concept of a continuum or a spectrum considering DSH at one extreme and suicide at the other. DSH, in this model, works as the antechambers of suicide, representing an independent risk factor for suicidal behavior. Evidence supporting this hypothesis (Sinclair and Green, 2005; Whitlock et al., 2013) highlights the strong co-occurrence between DSH and suicidal behavior.
The relationship between DSH and suicide attempts is still unclear, thus our aim was to clarify their connection by analyzing a sample of clinical patients and a community sample of students. In this way, we have analyzed two questions: 1) "Did adolescents want to die when they self-harmed?"; 2) "Does depression, anxiety, stress, suicidal ideation, and DSH predict suicide attempts in adolescents who self-harm?". In order to explore these questions, we resorted to a sample of clinical patients and a community sample of students.

\section{Methods}

\subsection{Participants}

This study analyzed a group composed of a community and a clinical sample. The community sample comprised of 502 adolescents from 4 Portuguese public schools. This sample presented $50.6 \%$ of female participants $(n=254)$, aged between 12 and 20 years $(M=16.33$, $S D=1.81$ ). The clinical sample consisted of 98 adolescents; $64.3 \%$ were female $(n=63)$, and aged between 12 and 21 years $(M=16.33$, $S D=1.91$ ). Adolescents in the clinical sample were attending psychiatric outpatient consultations in a multidisciplinary team-based approach to adolescents with mental health disorders at a public hospital in Lisbon. The patients from the clinical settings were randomly selected from outpatient settings for a period of three months. The total sample presented a mean age of 16.33 years old $(S D=1.83)$.

From the total sample, $61 \%$ of the participants lived with both parents, $26.3 \%$ lived only with their mothers, $5.2 \%$ with their fathers, $5.5 \%$ with other family members, $1.3 \%$ lived alone, and $0.7 \%$ lived in an institution.

The group was analyzed as a whole, comprised by both the community and the clinical sample. This was done considering that the cutoff for presentation at the clinical settings is higher than desirable. By merging both samples as one group it is possible to have a more reliable analysis of the real-life settings.

\subsection{Measures}

\subsubsection{Inventory of deliberate self-harm behaviors (ICAL)}

The ICAL was developed by Duarte et al. (2019a) and revealed acceptable psychometric properties ( $\alpha=0.91 ; M=1.96 ; S D=2.95$ ). This instrument presents 13 different DHS behaviors: cutting, biting, burning, pulling hair, scratching until the skin is wounded, consuming drugs with a self-aggressive intent, sticking self with needles, ingesting dangerous substances with a self-aggressive intent, drinking alcohol with a self-aggressive intent, banging/hitting, ingesting medication with a self-aggressive intent, ingesting medication with a suicidal intent, and attempting suicide. The lifetime frequency of each DSH behavior is evaluated in a four-option response format ("No", "Yes - 1 Time", "Yes, 2-10 Times", "Yes, More than 10 Times").

In order to analyze adolescents' intent to commit suicide when selfharming, the following question was made: "Did you want to die when you self-harmed?". Frequency responses ranged from 0 (never) to 4 (always) and the mean was $0.98(S D=1.95)$.

\subsubsection{Suicidal ideation questionnaire (SIQ)}

The SIQ (Reynolds, 1988) is a 30-item self-report scale that measures the current suicidal ideation for adolescents. Participants responded to items on a 7-point scale indicating the frequency of their suicidal thoughts. Responses range from 0 ("I never had the thought") to 6 ("almost every day"), creating a range of scores from 0 to 180 , where higher scores represent higher levels of suicidal ideation. The SIQ has demonstrated good internal consistency, as well as adequate concurrent and construct validity (Pinto et al., 1997). In the Portuguese adaptation, this questionnaire showed a Cronbach's alpha of 0.96 and an alpha of 0.76 in the test-retest reliability (Ferreira and Castela, 1999). In the present study, SIQ presented a Cronbach's alpha 
of 0.98 , with a mean of $34.35(S D=42.75)$.

According to Reynolds (1988) a score equal or higher than 41 may be indicative of significant potential risk of suicide. In the present article, we have used the Reynolds criterion and dichotomized this variable taking into consideration the threshold for suicide risk equal to 41 points. Therefore, participants with a SIQ score equal to or higher than 41 were grouped in the Suicide risk group (Reynolds, 1988).

\subsubsection{Suicide attempts}

In order to measure suicide attempts, participants answered the following question: "Did you ever attempted suicide?". Responses were given in a 4-point format: 0 (never), 1 (once), 2 (twice), and 3 (more than twice). From the total sample, $80.7 \%(n=444)$ reported never having attempted suicide, $8 \%(n=44)$ reported one, $4 \%(n=22)$ reported two, and $7.3 \%(n=40)$ reported more than two suicide attempts.

\subsubsection{Anxiety, depression, and stress scale (EADS-21)}

This scale was developed by Lovibond and Lovibond (1995) and adapted to the Portuguese population by Pais-Ribeiro et al. (PaisRibeiro et al., 2004). This is a self-report scale that evaluates the presence of symptoms of anxiety, depression, and stress. This instrument is composed of 21 items, which are evenly divided by each of the dimensions (i.e. 7 items in each dimension). Each item is an affirmation that refers to negative emotional symptoms that occurred in the previous week (e.g. "I felt I was not very valuable as a person" [Depression]; "I had difficulty breathing" [Anxiety]; "I tended to react too much in certain situations" [Stress]). Participants respond using a 4points scale $(0=$ "nothing applied to me" to $3=$ "applied to me most of the time"). The subscales presented good to very good values of internal consistency: anxiety $\alpha=0.89, M=7.45, S D=5.64$; depression $\alpha=0.91, M=6.27, S D=5.98$; and stress $\alpha=0.88, M=5.23$, $S D=5.48$.

\subsubsection{Socio-Demographic questionnaire}

Participants completed a socio-demographic questionnaire regarding their age, sex, nationality, education (number of academic retentions and school grade), the existence of siblings, and their parents' marital status.

\subsection{Procedures}

This study was approved by the General Education Directorate of the Ministry of Education and Science. The schools were contacted and informed about the objectives of the investigation. After receiving the schools' administration approval, several classes were selected. Initially, the researchers delivered the consent forms to the students' parents/ legal guardians as a letter home. Once consent was obtained, students then completed the questionnaire. All participants were informed that their collaboration was voluntary and that the collected data was anonymous and confidential.

\section{Results}

In the community sample, $205(40.8 \%)$ adolescents reported previous history of DSH, from which 145 (28.9\%) reported to have selfharmed using two or more DSH methods, and 59 (11.8\%) adolescents reported at least one previous suicide attempt. As for the clinical sample, $82(83.7 \%)$ adolescents reported DSH practices, from which 73 (74.5\%) reported multiple DSH methods, and 50 (52.1\%) adolescents had at least one previous suicide attempt. From the total sample, 314 (52.2\%) adolescents reported to never had self-harmed, whereas 288 $(47.8 \%)$ reported to have self-harmed at least once, and $218(36.2 \%)$ practiced two or more different DSH methods.

In order to test our first research question (i.e. "Did you want to die when you self-harmed?"), we explored whether there was a relationship
Table 1

Contingency table between adolescent DSH and suicide risk.

\begin{tabular}{llllll}
\hline \multicolumn{5}{c}{ Self-harm behavior } & \multicolumn{2}{l}{ Total } & $\chi^{2}$ \\
\hline \multirow{2}{*}{ Suicide risk } & No & $289(70.0 \%)$ & $124(30.0 \%)$ & $413(100 \%)$ & $168.43^{* * * *}$ \\
& Yes & $24(12.8 \%)$ & $163(87.2 \%)$ & $187(100 \%)$ & \\
& Total & $313(52.2 \%)$ & $287(47.8 \%)$ & $600(100 \%)$ & \\
\hline
\end{tabular}

Note. $\chi^{2}=$ Chi-Square test; ${ }^{* * *} p<.001$.

between lifetime prevalence of DSH and an SIQ score equal or higher than 41 (suicide risk). The contingency table showed in Table 1 presents a statistically significant association between these two variables $\left(\chi_{(1)}^{2}=168.43, p<.001\right)$, where the proportion of adolescents at risk of suicide with DSH ( $n=163,87.2 \%$ ) is significantly higher than the proportion of adolescents at risk of suicide without DSH ( $n=24$, $12.8 \%)$. This table also shows a third group of 124 (30.0\%) adolescents' self-harmers without suicide risk and a fourth group with neither DSH nor suicide risk.

In order to further explore the potential suicidal ideation of adolescents who self-harm, we considered the variable where we asked participants with history of DSH ( $n=287,47.8 \%$ ) whether or not they wanted to die when they self-harmed (i.e. "Did you want to die when you self-harmed?"). These results showed that 63 participants (35.2\%) reported they never wanted to die while self-harming, with the remaining $116(64.8 \%)$ reporting the wish to die during the self-harming experience (rarely $n=31$; sometimes $n=44$; almost always $n=25$; always $n=16$ ). The Chi-square test, present in Table 2, showed a statistically significant association between suicide risk and the wish to die during self-harming behaviors $\left(\chi_{(1)}^{2}=71.49, p<.001\right)$, where the proportion of adolescents wishing to die in the no suicide risk group ( $n=19,16.4 \%$ ) was significantly lower than the proportion of adolescents wishing to die in the suicide risk group ( $n=97,83.6 \%)$.

In a second step, we considered the adolescents' suicide attempts and its relation to DSH.

As much as $52 \%(n=51)$ of the clinical group and $11.8 \%(n=59)$ of the community group reported suicide attempts. Overall, $18.3 \%$ ( $n=110$ ) of the total sample reported suicide attempts. The Chi-Square analysis for these variables presented in Table 3 revealed that, while 109 (99.1\%) adolescents' self-harmers reported suicide attempts, only 1 (0.9\%) adolescent without DSH reported suicide attempts. The results in Table 3 seem to present three different groups of adolescents, i.e. G1 - Non-suicidal non-self-harmers ( $n=313$, 52\%); G2 - Non-suicidal selfharmers ( $n=177,29.4 \%)$; and G3 - Suicidal self-harmers ( $n=109$, $38.1 \%)$.

Further analyzes exploring the differences between these three groups revealed statistically significant mean differences of suicidal ideation $\left(F_{(2)}=359.99, p<.001\right)$, number of DSH behaviors $\left(F_{(2)}=540.131, p<.001\right)$, depression $\left(F_{(2)}=129.05, p<.001\right)$, anxiety $\left(F_{(2)}=123.73, p<.001\right)$, and stress $\left(F_{(2)}=97.34, p<.001\right)$. Throughout all these comparison analyzes, the G1-Non-suicidal non-selfharmers group presented the lower means, followed by the G2-Nonsuicidal self-harmers group, and finally the G3-Suicidal self-harmers presenting the highest means.

Post-hoc analyzes revealed that the means of all three groups were

Table 2

Contingency table between adolescent suicide risk and wish to die during DSH.

\begin{tabular}{llllll}
\hline & \multicolumn{3}{c}{ Suicide risk } & & \\
& & No & Yes & Total & $\chi^{2}$ \\
\hline \multirow{2}{*}{ Wished to die } & No & $51(81.0 \%)$ & $19(19.0 \%)$ & $63(100 \%)$ & $71.49^{* * * *}$ \\
& Yes & $19(16.4 \%)$ & $97(83.6 \%)$ & $116(100 \%)$ & \\
& Total & $70(39.1 \%)$ & $109(60.9 \%)$ & $179(100 \%)$ & \\
\hline
\end{tabular}

Note. $\chi^{2}=$ Chi-Square test; ${ }^{* * *} p<.001$. 
Table 3

Contingency table between suicide attempts and self-harm behaviors.

\begin{tabular}{|c|c|c|c|c|c|}
\hline & & \multicolumn{4}{|c|}{ Self-harm behavior } \\
\hline & & No & Yes & Total & $\chi^{2}$ \\
\hline \multirow[t]{3}{*}{ Suicide attempt } & No & $313(63.9 \%)$ & 177 (36.1\%) & $490(100 \%)$ & $142.79^{* * * *}$ \\
\hline & Yes & $1(0.9 \%)$ & 109 (99.1\%) & $110(100 \%)$ & \\
\hline & Total & $314(52.3 \%)$ & $286(47.7 \%)$ & $600(100 \%)$ & \\
\hline
\end{tabular}

Note. $\chi^{2}=$ Chi-Square test; ${ }^{* * *} p<.001$.

significantly different $(p<.001)$ from each other for suicidal ideation (G1 $M=11.17, S D=20.15 ; \mathrm{G} 2 \quad M=35.85, S D=34.34 ; \mathrm{G} 3$ $M=97.08, S D=38.11$ ), diversity of DSH methods (G1 $M=0.00$, $S D=000 ; \mathrm{G} 2 M=2.74, S D=1.79$; G3 $M=6.25, S D=3.42)$, depression (G1 $M=3.75, S D=4.45$; G2 $M=6.68, S D=5.22$; G3 $M=12.66, S D=5.96$ ), anxiety (G1 $M=2.91, S D=3.74 ; \mathrm{G} 2$ $M=5.82, S D=5.05 ; \mathrm{G} 3 M=10.93, S D=5.92$ ), and stress (G1 $M=5.10, S D=4.62 ; \mathrm{G} 2 M=8.50, S D=4.77 ; \mathrm{G} 3 \quad M=12.48$, $S D=5.77)$. Since these variables took form in such different ranges (e.g. suicidal ideation questionnaire 0-180, depression 1-5), Fig. 1 illustrates the present findings in the form of Z-scores.

As shown in Table 3, virtually all adolescents with suicide attempts also reported DSH. However, not all self-harmer adolescents reported previous suicide attempts; hence two groups of adolescents who selfharm emerge (i.e., G2-Non-suicidal self-harmers and G3-Suicidal selfharmers). Therefore, with our second research question (i.e. "depression, anxiety, stress, suicidal ideation, and number of self-harm behaviors predict suicide attempts in adolescent self-harmers?") we tried to develop a model (which also included sex and age as predictors) to predict the G3-Suicidal self-harmers, as opposed to G2-Non-suicidal selfharmers, as shown in Table 4.

In order to explore our second research question, we developed a Logistic Model, in which we included depression, anxiety, stress, sex, and age on Block 1; suicidal ideation and diversity of DSH behaviors were entered on Block 2 (Table 4). The first Block significantly predicted suicidal self-harmers $\left(\chi_{(5)}^{2}=70.652, p>.001\right)$, explaining $30 \%$ of the variance $\left(R^{2}=0.302\right)$. An analysis of the individual contribution of each factor shows depression (Exp (B) $=1.150,95 \%$ CI 1.079-1.225, $p<.001)$ and anxiety (Exp (B) $=1.102,95 \%$ CI 1.025-1.185, $p<.01)$ as significant predictors of suicide attempts in adolescent self-harmers. The global model (i.e. Block $2 ; \chi_{(7)}^{2}=156.855, p>$.001) significantly
Table 4

Logistic Regression Model to predict suicide attempts in adolescent with lifetime prevalence of self-harm behaviors.

\begin{tabular}{lllllllll}
\hline & B & Wald & Exp(b) & \multicolumn{2}{l}{$95 \%$ CI for B } & $\chi^{2}$ & $R^{2}$ \\
& & & & Lower & \multicolumn{2}{l}{ Upper } \\
Bound & Bound & & \\
\hline Block 1 & & & & & & & \\
Depression & .140 & 18.625 & $1.150^{* * *}$ & 1.079 & 1.225 & $70.652^{* * *}$ & .302 \\
Anxiety & .097 & 6.855 & $1.102^{* * *}$ & 1.025 & 1.185 & & \\
Stress & -0.035 & .695 & .966 & .890 & 1.048 & & \\
Sex & .020 & .004 & 1.020 & .563 & 1.849 & & \\
Age & -0.031 & .153 & .969 & .829 & 1.134 & & \\
Block 2 & & & & & & & \\
Depression & .033 & .587 & 1.033 & .950 & 1.123 & $156.855^{* * * *}$ & .581 \\
Anxiety & .049 & 1.025 & 1.050 & .955 & 1.154 & & \\
Stress & -0.073 & 1.958 & .930 & .840 & 1.030 & & \\
Sex & .466 & 1.546 & 1.594 & .764 & 3.326 & & \\
Age & -0.048 & .235 & .953 & .786 & 1.157 & & \\
Suicidal & .030 & 28.536 & $1.031^{* * * *}$ & 1.019 & 1.042 & & \\
$\quad$ ideation & & & & & & & \\
DSH & .313 & 17.239 & $1.367^{* * * *}$ & 1.179 & 1.584 & & \\
$\quad$ diversity & & & & & & & \\
\hline
\end{tabular}

Predictors: $\operatorname{sex}(0=$ female; $1=$ male $) .{ }^{* *}=p<.01 ;{ }^{* * *} p<.001$.

predicted suicidal self-harmers explaining $58 \%$ of the variance $\left(R^{2}=0.581\right)$. Statistically significant individual contributions were given by suicidal ideation (Exp (B) $=1.031,95 \%$ CI 1.019-1.042, $p<.001)$ and diversity of DSH behaviors (Exp (B) $=1.367,95 \% \mathrm{CI}$ 1.179-1.584, $p<.001$ ).

\section{Discussion}

This study intended to explore the interaction between suicidal ideation and DSH by analyzing a sample of clinical patients and a community sample of students. As previously stated, self-harm behaviors are often related with suicidal ideation and suicide attempts, and constitute the main risk factor for suicide. Our findings are consistent with this hypothesis. In fact, our results showed that only one adolescent presented suicide attempts without previous DSH behaviors, which comes in line with our research questions, where DSH can be a precursor expression of suicidal attempts. It is also important to highlight that suicide risk (SIQ score equal or higher than 41) was present in 19\% of adolescents who reported no desire to die during previous DSH. On

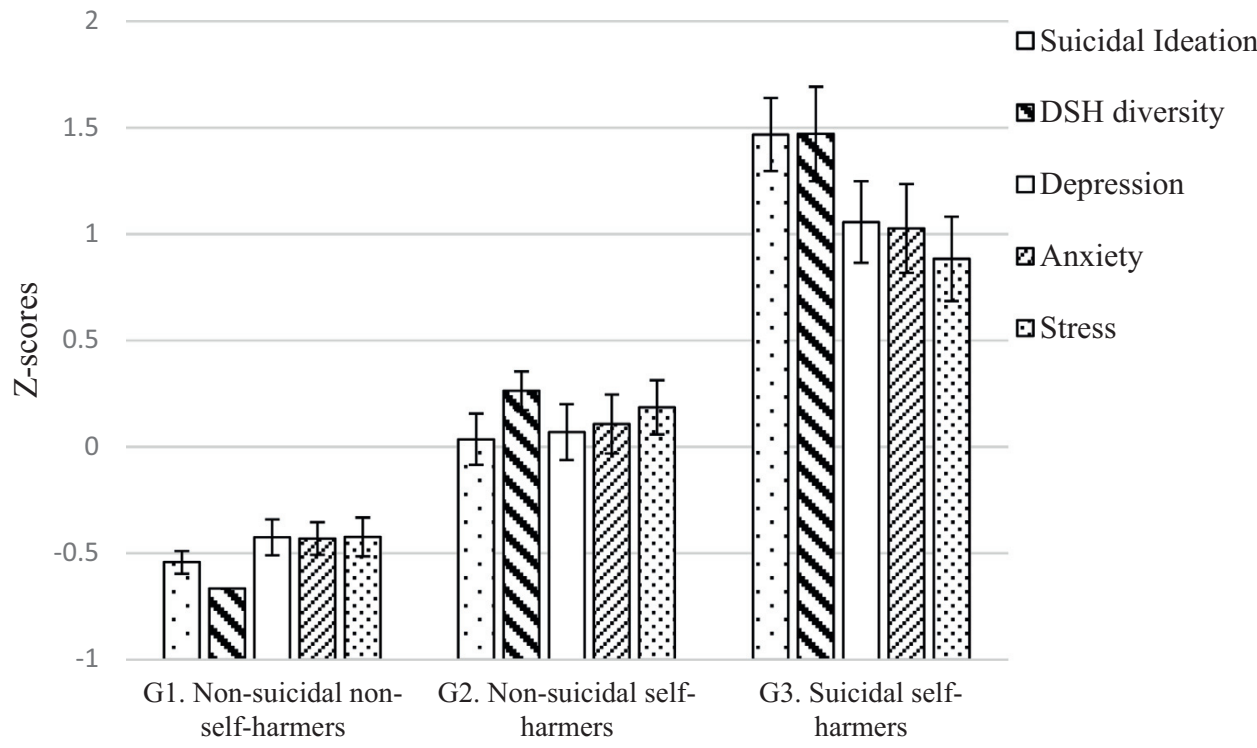

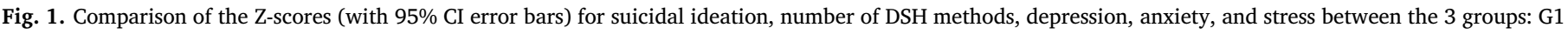
Non-suicidal non-self-harmers; G2-Non-suicidal self-harmers; G3-Suicidal self-harmers. 
the other hand, $16.4 \%$ of the adolescents wished to die while selfharming but had no suicide risk. This may take into account the presence of protective factors like family alliance, suicide-related concerns, or spirituality (Brenton et al., 2015).

Our findings point to the fact that there is considerable overlap between DSH with and without suicidal intent, as half of the individuals (56.8\%) with DSH had significant suicide risk and most of them wished to die during these behaviors. Our data presented a direct association between DSH and suicide attempts, with $99.1 \%$ of the adolescents with suicide attempts also reporting DSH. So, our results seem to suggest a continuum between DSH and suicidal behaviors, in which DSH precede suicide attempts, thus placing DSH in a key position for early intervention. This overlap between DSH with and without suicidal intent, has led other researchers to argue that they are best conceptualized along a continuum (Stanley et al., 1992; Kapur et al., 2013). In a study by Nock et al., among those with a history of DSH, 70\% had attempted suicide at least once and 55\% several times (Nock et al., 2006). In fact, many individuals engage in both behaviors (Hamza et al., 2012; Klonsky et al., 2013; Mars et al., 2014).

As much as $31.2 \%(n=187)$ of the total sample were at suicide risk which is alarming as the majority of the sample is not from a clinical setting. It is possible that neuro-developmental vulnerabilities during adolescence linked to the onset of mood and substance use disorders, risk-taking behaviors, or heightened susceptibility to negative social cues contribute to the relatively high suicide risk during adolescence (O'Connor et al., 2010; Sebastian et al., 2010).

There may be intrapersonal reasons (e.g., negative affects' relief, feelings' seeking to reduce the experience of anhedonia) or interpersonal reasons (e.g., disease's communication, help request, escape from a difficult situation) for DSH behaviors (Ayub and Arabia, 2015). In fact, Duarte et al. (2019b) conducted a study with the aim of comparing the social representations about the functions of DSH between a group of adolescents with DSH and another without DSH and their respective parents. Results revealed significant differences between both groups of families, implying that the groups of participants represent the functions of deliberate self-harm differently. Overall, parents emphasized interpersonal functions and devalued intrapersonal functions while adolescents with DSH emphasized intrapersonal functions, in particular affect regulation.

As previously stated, depression has been found to be strongly associated with suicidal self-harm (Cloutier et al., 2010; Jacobson et al., 2008; Wichstrøm, 2009). Despite previous research regarding anxiety (Cloutier et al., 2010; Jacobson et al., 2008; Larsson and Sund, 2008) has failed to produce any clear conclusions, our study comes in line with the findings from Guerreiro et al. (Guerreiro et al., 2017), concluding that depression and anxiety are positively related with suicide attempts in self-harmer adolescents. However, our results showed that when suicidal ideation and diversity of DSH are included in the prediction model, these two last variables become the only significant predictors of suicide attempts. Taking into consideration these results, for each increment of a SIQ unit the ratio of chances to attempt suicide increases by $3.1 \%$. If we consider that the scale ranges from 0 to 180 , for each increment of 10 points, the probability of attempting suicide increases by $31 \%$. In the case of the diversity of DSH, for each increment of different DSH behavior the probability of attempting suicide increases by $36.7 \%$.

Present results show the importance of analyzing suicidal ideation and the diversity of DSH methods, insofar as these variables seem to constitute a high risk for future suicidal behavior. This goes in line with Joiner's Theory (Joiner, 2005) that the repetition of DSH might disrupt the pathways involved in the stress-induced analgesia that leads to pain tolerance. DSH might thus enable the person to become accustomed and thus desensitized to the fear and pain of physically hurting oneself (Hamza et al., 2012; Joiner et al., 2009). Thus, our results on the diversity of DSH methods reveals seem to us very important for the understanding of DSH and for clinical intervention. Moreover, our findings are consistent with Victor and Klonsky (Victor and Klonsky, 2014b) and Wilkinson et al. (Wilkinson et al., 2011) results that showed a strong association between the diversity of DSH methods and the risk of suicide attempts in adolescents.

\subsection{Conclusion}

Depression and anxiety emerge as significant predictors of suicide attempts in self-harmer adolescents. This demonstrates the need to target these factors as early as possible to prevent suicide. From the present study, we highlight the fact that suicidal ideation and the diversity of methods of DSH behaviors influence the risk for suicide attempts, with both an augmentation in the diversity of methods of DSH and suicidal ideation predicting suicide attempts. Nonetheless, more studies should emphasize the relationship between an increased diversity of DSH and suicidal ideation.

These results are important for the clinical practice as it is essential to evaluate suicidal ideation in adolescents who self-harm. In line with previous studies, the need for suicide prevention should be highlighted despite the presence or absence of obvious suicidal intention in the act.

\subsection{Limitations}

This study was based on self-reported data and may therefore be affected by inaccuracies including recall bias, social desirability, and so forth. Participants may also have felt uncomfortable disclosing suicidal thoughts and behaviors and chosen not to disclose them. A second limitation concerns the difficulty in measuring suicidal intent. In line with previous research (Nock, 2010), individuals were classified according to self-reported lifetime suicidal intent; however, reports may be affected by current mood state. A third limitation concerns the fact that this study was based on cross-sectional designs, which may result in a narrow view of the problem and longitudinal studies may enlighten the continuity between DSH and suicide attempts.

The relationship between suicidal intent and DSH diversity is complex. It is possible that those who have self-harmed on multiple occasions are more likely to have self-harmed with suicidal intent. If so, this could provide an alternative explanation for some of the differences in associations found.

This research did not receive any specific grant from funding agencies in the public, commercial, or not-for-profit sectors. Hugo S. Gomes was supported by a doctoral grant from the Portuguese Foundation for Science and Technology (FCT - SFRH/BD/122,919/ 2016).

\section{Declaration of Competing Interest}

The authors certify that they have NO affiliations with or involvement in any organization or entity with any financial interest (such as honoraria; educational grants; participation in speakers' bureaus; membership, employment, consultancies, stock ownership, or other equity interest; and expert testimony or patent-licensing arrangements), or non-financial interest (such as personal or professional relationships, affiliations, knowledge or beliefs) in the subject matter or materials discussed in this manuscript.

\section{Supplementary materials}

Supplementary material associated with this article can be found, in the online version, at doi:10.1016/j.psychres.2019.112553.

\section{References}

American Psychiatric Association, 2013. The Diagnostic and Statistical Manual of Mental Disorders, 5th ed. American Psychiatric Association, Washington.

Ayub, N., Arabia, S., 2015. Predicting suicide ideation through intrapersonal and 
interpersonal factors: the interplay of big-five personality traits and social support. Personal. Ment. Health 9 (4), 308-318. https://doi.org/10.1002/pmh.1301.

Barreto Carvalho, C., da Motta, C., Sousa, M., Cabral, J., 2017. Biting myself so i don't bite the dust: prevalence and predictors of deliberate self-harm and suicide ideation in azorean youths. Revista Brasileira de Psiquiatria 39 (3), 252-262. http://dx.doi.org/ 10.1590/1516-4446-2016-1923.

Bilsen, J., 2018. Suicide and youth: risk factors. Front. Psychiatry 9, 540. https://doi.org/ 10.3389/fpsyt.2018.00540.

Brausch, A.M., Gutierrez, P.M., 2010. Differences in non-suicidal self-injury and suicide attempts in adolescents. J. Youth Adolesc. 39 (3), 233-242. http://dx.doi.org/10. 1007/s10964-009-9482-0.

Brenton, J.J., Labelle, R., Berthiaume, C., Royer, C., St-Georges, M., Ricard, D., Abadie, P., Gérardin, P., Cohen, D., Guilé, J.M., 2015. Protective factors against depression and suicidal behaviour in adolescence. Ca. J. Psychiatry 60 (2 Supple 1), S5-S15.

Carvalho, A., Peixoto, B., Saraiva, C.B., 2013. Plano nacional de prevenção do suicídio 2013/2017. Direcção Geral de Saúde, Lisbon.

Castellví, P., Lucas-Romero, E., Miranda-Mendizábal, A., Parés-Badell, O., Almenara, J. Alonso, I., Blasco, M.J., Cebrià, A., Gabilondo, A., Gili, M., Lagares, C., Piqueras, J.A., Roca, M., Rodriguez-Marín, J., Rodríguez Jimenez, T., Soto-Sanz, V., Alonzo, J., 2017. Longitudinal association between self-injurious thoughts and behaviors and suicidal behavior in adolescents and young adults: a systematic review with metaanalysis. J. Affect. Disord. 215, 37-48. http://dx.doi.org/10.1016/j.jad.2017.03.035.

Cloutier, P., Martin, J., Kennedy, A., Nixon, M.K., Muehlenkamp, J.J., 2010. Characteristics and co-occurrence of adolescent non-suicidal self-injury and suicidal behaviours in pediatric emergency crisis services. J. Youth Adolesc. 39, 259-269. http://dx.doi.org/10.1007/s10964-009-9465-1.

Costa, A.C.B., Mariusso, L.M., Canassa, T.L., Previdelli, I.T.S., Porcu, M., 2019. Risk factors for suicidal behavior in a university population in brazil: a retrospective study. Psychiatry Res. 278, 129-134. https://doi.org/10.1016/j.psychres.2019.05. 039.

Cruz, D., Narciso, I., Muñoz, M., Pereira, C.R., Sampaio, D., 2013. Adolescents and selfdestructive behaviours: an exploratory analysis of family and individual correlates. Behav. Psychol./Psicol. Conduct. 21 (2), 271-288.

Di Pierro, R., Sarno, I., Perego, S., Gallucci, M., Madeddu, F., 2012. Adolescent self-injury: personality traits, family relationships, and maltreatment on presence and severity of behaviors. Euro. Child Adolesc. Psychiatry 21 (9), 511-520. http://dx.doi.org/10. 1007/s00787-012-0289-2.

Duarte, E., Gouveia-Pereira, M., Gomes, H., 2019. Portuguese development and factorial validation of the inventory of deliberate self-harm behaviours for portuguese Portuguese adolescents. Manuscript submitted for publication.

Duarte, E., Gouveia-Pereira, M., Gomes, H., Sampaio, D., 2019b. How do families represent the functions of deliberate self-harm? a comparison between the social representations from adolescents and their parents. Arch. Suicide Res. 3, 1-10. http:// dx.doi.org/10.1080/13811118.2018.1545713.

Ferreira, J.A., Castela, M.C., 1999. Questionário de ideação suicida (Q.I.S) [Questionnaire of suicidal ideation]. In: Simões, M.R., Gonçalves, M.M., Almeida, L.S. (Eds.), Testes e provas psicológicas em Portugal. Sistemas Humanos e Organizacionais, Lda., Braga, pp. 129-130.

Ghinea, D., Koenig, J., Parzer, P., Brunner, R., Carli, V., Hoven, C.W., Sarchiapone, M., Wasserman, D., Resch, F., Kaess, M., 2019. Longitudinal development of risk-taking and self-injurious behavior in association with late adolescent borderline personality disorder symptoms. Psychiatry Res. 273, 127-133. https://doi.org/10.1016/j. psychres.2019.01.010.

Gonçalves, S., Martins, C., Rosendo, A.P., Machado, B.C., Silva, E., 2012. Self-injurious behavior in Portuguese adolescents. Psicothema 24 (4), 536-541.

Gouveia-Pereira, M., Abreu, S., Martins, C., 2014. How do families of adolescents with suicidal ideation behave? Psicologia: Reflexão e Crítica 27 (1), 171-178. http://dx doi.org/10.1590/S0102-79722014000100019.

Grandclerc, S., De Labrouhe, D., Spodenkiewicz, M., Lachal, J., Moro, M.R., 2016. Relations between nonsuicidal self-injury and suicidal behavior in adolescence: a systematic review. PLoS ONE 11 (4), e0153760. http://dx.doi.org/10.1371/journal. pone. 0153760 .

Guerreiro, D.F., Sampaio, D., Figueira, M.L., Madge, N., 2017. Self-Harm in adolescents: a self-report survey in schools from Lisbon, Portugal. Arch. Suicide Res. 21 (1), 83-99. http://dx.doi.org/10.1080/13811118.2015.1004480.

Gutridge, K., 2010. Safer self-injury or assisted self-harm? Theor. Med. Bioeth. 31 (1), 79-92. http://dx.doi.org/10.1007/s11017-010-9135-z.

Hamza, C.A., Stewart, S.L., Willoughby, T., 2012. Examining the link between nonsuicidal self-injury and suicidal behavior: a review of the literature and an integrated model. Clin. Psychol. Rev. 32, 482-495. http://dx.doi.org/10.1016/j.cpr.2012.05.003.

Hamza, C.A., Willoughby, T., Heffer, T., 2015. Impulsivity and nonsuicidal self-injury: a review and meta-analysis. Clin. Psychol. Rev. 38, 13-24. http://dx.doi.org/10.1016/ j.cpr.2015.02.010.

Jacobson, C.M., Muehlenkamp, J.J., Miller, A.L., Turner, J.B., 2008. Psychiatric impairment among adolescents engaging in different types of deliberate self- harm. J. Clin. Child Adolesc. Psychol. 37, 363-375. http://dx.doi.org/10.1080/ 15374410801955771.

Joiner, T., 2005. Why people die by suicide. Harvard University Press, Cambridge.

Joiner Jr, T.E., Van Orden, K.A., Witte, T.K., Selby, E.A., Ribeiro, J.D., Lewis, R., Rudd, M.D., 2009. Main predictions of the interpersonal-psychological theory of suicidal behavior: empirical tests in two samples of young adults. J. Abnorm. Psychol. 118, 634-646. http://dx.doi.org/10.1037/a0016500.

Kapur, N., Cooper, J., O'Connor, R.C., Hawton, K., 2013. Non-suicidal self-injury v. attempted suicide: new diagnosis or false dichotomy? Br. J. Psychiatry 202, 326-328. http://dx.doi.org/10.1192/bjp.bp.112.116111.

Kelada, L., Hasking, P., Melvin, G., 2016. The relationship between nonsuicidal self-injury and family functioning: adolescent and parent perspectives. J. Marital Fam. Ther. 42 (3), 536-549. https://doi.org/10.1111/jmft.12150.

Kiekens, G., Bruffaerts, R., Nock, M.K., Van de Ven, M., Witteman, C., Mortier, P., Claes, L., 2015. Non-suicidal self-injury among Dutch and Belgian. Euro. Psychiatry 30 (6), 743-749. https://doi.org/10.1016/j.eurpsy.2015.06.007.

Klemera, E., Brooks, F.M., Chester, K.L., Magnusson, J., Spencer, N., 2017. Self-harm in adolescence: protective health assets in the family, school and community. Int. J. Public Health 62 (6), 631-638. https://doi.org/10.1007/s00038-016-0900-2.

Klonsky, E.D., May, A.M., Glenn, C.R., 2013. The relationship between nonsuicidal selfinjury and attempted suicide: converging evidence from four samples. J. Abnorm. Psychol. 122, 231-237. https://doi.org/10.1037/a0030278.

Larsson, B., Sund, A.M., 2008. Prevalence, course, incidence, and 1-year prediction of deliberate self-harm and suicide attempts in early norwegian school adolescents. Suicide Life-Threat. Behav. 38, 152-165. https://doi.org/10.1521/suli.2008.38.2. 152.

Lee, W.K., 2016. Psychological characteristics of self-harming behavior in Korean adolescents. Asian J. Psychiatr. 23, 119-124. http://dx.doi.org/10.1016/j.ajp.2016.07. 013.

Linehan, M., 1993. Cognitive-behavioral Treatment of Borderline Personality Disorder. The Guilford Press, New York.

Lipschitz, J., Yen, S., Weinstock, L., Spirito, A., 2012. Adolescent and caregiver perception of family functioning: relation to suicide ideation and attempts. Psychiatry Res. 200 (2-3), 400-403. http://dx.doi.org/10.1016/j.psychres.2012.07.051.

Lovibond, S.H., Lovibond, P.F., 1995. Manual For the Depression Anxiety Stress Scales. Psychology Foundation of Australia, Sydney.

Madge, N., Hawton, K., Mcmahon, E.M., 2011. Psychological characteristics, stressful life events and deliberate self-harm: findings from the child and adolescent self-harm in Europe (CASE) study. Euro. Child Adolesc. Psychiatry 20, 499-508. https://doi.org/ 10.1007/s00787-011-0210-4.

Mars, B., Heron, J., Crane, C., 2014. Differences in risk factors for self-harm with and without suicidal intent: findings from the ALSPAC cohort. J. Affect. Disord. 168, 407-414. http://dx.doi.org/10.1016/j.jad.2014.07.009.

McMahon, E.M., Reulbach, U., Corcoran, P., Keeley, H.S., Perry, I.J., Arensman, E., 2010 Factors associated with deliberate self-harm among Irish adolescents. Psychol. Med. 40 (11), 1811-1819. https://doi.org/10.1017/S0033291709992145.

Meszaros, G., Horvath, L.O., Balazs, J., 2017. Self-injury and externalizing pathology: a systematic literature review. BMC Psychiatry 17 (1), 160. https://doi.org/10.1186/ s12888-017-1326-y.

Muehlenkamp, J.J., Claes, L., Havertape, L., Plener, P.L., 2012. International prevalence of adolescent non-suicidal self-injury and deliberate self-harm. Child Adolesc. Psychiatry Ment. Health 6 (1), 1-9. https://doi.org/10.1186/1753-2000-6-10.

Muehlenkamp, J.J., Gutierrez, P.M., 2007. Risk for suicide attempts among adolescents who engage in non-suicidal self-injury. Arch. Suicide Res. 11 (1), 69-82. https://doi. org/10.1080/13811110600992902.

Naghavi, M., 2019. Global, regional, and national burden of suicide mortality 1990 to 2016: systematic analysis for the global burden of disease study 2016. BMJ 364, 194. https://doi.org/10.1136/bmj.194.

Nock, M.K., 2009. Why do people hurt themselves? new insights into the natural and functions of self-injury. Curr. Dir. Psychol. Sci 18, 78-83. https://doi.org/10.1111/j. 1467-8721.2009.01613.x.

Nock, M.K., 2010. Self-injury. Annu. Rev. Clin. Psychol. 6, 339-363. https://doi.org/10. 1146/annurev.clinpsy.121208.131258.

Nock, M.K., Borges, G., Bromet, J.E., Cha, C.B., Kessler, R.K., Lee, S., 2008. Suicide and suicidal behavior. Epidemiol. Rev. 30 (1), 133-154. https://doi.org/10.1093/epirev/ mxn002.

Nock, M.K., Joiner, T.E., Gordon, K.H., Lloyd-Richardson, E., Prinstein, M.J., 2006a. Nonsuicidal self-injury among adolescents: diagnostic correlates and relation to suicide attempts. Psychiatry Res. 144 (1), 65-72. https://doi.org/10.1037/a0029429.

O'Connor, R.C., Rasmussen, S., Hawton, K., 2010. Predicting depression, anxiety and selfharm in adolescents: the role of perfectionism and acute life stress. Behav. Res. Ther. 48 (1), 52-59. https://doi.org/10.1016/j.brat.2009.09.008.

Paashaus, L., Forkmann, T., Glaesmer, H., Juckel, G., Rath, D., Schönfelder, A., Engel, P., Teismann, T., 2019. Do suicide attempters and suicide ideators differ in capability for suicide? Psychiatry Res. 275, 304-309. https://doi.org/10.1016/j.psychres.2019.03. 038.

Pais-Ribeiro, J.L., Honrado, A., Leal, I., 2004. Contribuição para o estudo da adaptação portuguesa das escalas de ansiedade, depressão e stress (EADS) de 21 itens de Lovibond e Lovibond [Contribution to the study of the Portuguese adaptation of the Lovibond and Lovibond depression, anxiety, and stress scales (EADS-21) with 21 items]. Psicologia, Saúde e Doença 5 (2), 229-239.

Pinto, A., Whisman, M.A., McCoy, K.J.M., 1997. Suicidal ideation in adolescents: psychometric properties of the suicidal ideation questionnaire in a clinical sample. Psychol. Assess 9, 63-66.

Preyde, M., Watkins, H., Csuzdi, N., Carter, J., Lazure, K., White, S., Penney, R. Ashbourne, G., Cameron, G., Frensch, K., 2012. Non-suicidal self-injury and suicidal behaviour in children and adolescents accessing residential or intensive home-based mental health services. J. Canadian Acad. Child Adolesc. Psychiatry 21, 270-281.

Reynolds, W., 1988. Suicidal Ideation questionnaire: Professional manual. Psychological Assessment Resources Inc., Odessa.

Sebastian, C., Viding, E., Williams, K.D., Blakemore, S.J., 2010. Social brain development and the affective consequences of ostracism in adolescence. Brain. Cogn. 72 (1) 134-145. https://doi.org/10.1016/j.bandc.2009.06.008.

Sinclair, J., Green, J., 2005. Understanding resolution of deliberate self-harm: qualitative interview study of patients' experiences. BMJ 330 (7500), 1112-1115. https://doi. org/10.1136/bmj.38441.503333.8F.

Stanley, B., Winchel, R., Molcho, A., Simeon, D., Stanley, M., 1992. Suicide and the self- 
harm continuum: phenomenological and biochemical evidence. Int. Rev. Psychiatry 4, 149-155. http://dx.doi.org/10.3109/09540269209066312.

Victor, S.E., Klonsky, E.D., 2014a. Correlates of suicide attempts among self-injurers: a meta-analysis. Clin. Psychol. Rev. 34 (4), 282-297. https://doi.org/10.1016/j.cpr. 2014.03.005.

Victor, S.E., Klonsky, E.D., 2014b. Daily emotion in non-suicidal self-injury. J. Clin. Psychol. 70 (4), 364-375. https://doi.org/10.1002/jclp.22037.

Wasserman, D., Cheng, Q., Jiang, G.X., 2005. Global suicide rates among young people aged 15-19. World Psychiatry 4, 114-120.

Whitlock, J., Muehlenkamp, J., Eckenrode, J., Purington, A., Baral Abrams, G., Barreira, P., 2013. Nonsuicidal self-injury as a gateway to suicide in young adults. J. Adolesc. Health 52 (4), 486-492. https://doi.org/10.1016/j.jadohealth.2012.09.010.

Wichstrøm, L., 2009. Predictors of non-suicidal self-injury versus attempted suicide: similar or different? Arch. Suicide Res. 13, 105-122. https://doi.org/10.1080/ 13811110902834992.

Wilkinson, P., Kelvin, R., Roberts, C., Dubicka, B., Goodyer, I., 2011. Clinical and psychosocial predictors of suicide attempts and nonsuicidal self-injury in the adolescent depression antidepressants and psychotherapy trial (ADAPT). Am. J. Psychiatry 168, 495-501. https://doi.org/10.1176/appi.ajp.2010.10050718.

World Health Organization. 2018. WHO global health observatory data repository. http://apps.who.int/gho/data/node.main.MHSUICIDEAGEGROUPS15293015? lang $=$ en. Accessed 30 June 2019.

Zubrick, S.R., Hafekost, J., Johnson, S.E., Sawyer, M.G., Patton, G., Lawrence, D., 2017. The continuity and duration of depression and its relationship to non-suicidal selfharm and suicidal ideation and behavior in adolescents. J. Affect. Disord. 220, 49-56. https://doi.org/10.1016/j.jad.2017.05.050. 